\title{
Esthetic Analyses in Dentistry
}

\author{
Sadık H Uluçam ${ }^{1}$, Özlem Acar ${ }^{2}$
}

\begin{abstract}
Advances in technology and material development in dentistry and increased use of social media in recent years have raised the esthetic and cosmetic expectations of patients. Today's dentist should, therefore, be able to blend the concepts of ethics and esthetics. Examination of esthetic analysis by dividing into sections, such as facial analysis, dentolabial analysis, dental analysis, and phonetic analysis; and knowing these criteria well will provide a great advantage to the clinician in terms of planning and meeting the patient expectations.
\end{abstract}

Keywords: Esthetics, Esthetic dentistry, Smile design.

International Journal of Prosthodontics and Restorative Dentistry (2019): 10.5005/jp-journals-10019-1238

\section{INTRODUCTION}

In recent years, the number of patients demanding esthetic and cosmetic treatments have raised dramatically by the effect of frequent usage of social media in every aspect of our lives. The aim of this study is to provide useful information to clinicians while dealing with patients demanding esthetic and/or cosmetic treatments. Treatments comprising esthetic analyses will provide the clinician an artistic perspective in accordance with professional ethics. At the same time, this can increase patient satisfaction by meeting the subjective esthetic expectation of the patient with objective data and criteria.

The term of "esthetic" is derived from Greek word of perception. It can be described as "relating to the appreciation of the beauty", and is a branch under the science of philosophy. Esthetics refers to beauty and is artistically interested in beauty. The concept of beauty, on the other hand, can be examined in two ways as subjective and objective. The subjective perception of beauty is the ability of a person to call an object that he/she relates to oneself or an object that he/she likes emotionally. The objective perception of beauty is that object perfectly harmonizing with the form that complies with or that has to comply with the criteria promised previously or the criteria accepted by the majority over time is regarded as beautiful. ${ }^{1}$

In dentistry, esthetics can be defined as a harmony of esthetic dentistry and professional ethics. While the concept of esthetic dentistry is subjective, professional ethics is a concept of objective criteria and the rules to be followed. In dentistry, in a dental restoration, the philosophy and method obtained by the shape and/or color of the restoration, especially regarding the appearance of the restoration, is defined as esthetics. ${ }^{1}$ In recent years, most patients' major concern when consulting a dentist is to improve their smile esthetics.

The smile is one of the most important facial expressions and is defined as the non-verbal parameter of communication in body language. ${ }^{2,3}$ The effect of a smile on facial esthetics has been accepted by society. A beautiful smile reflects a certain lifestyle. Studies have shown that a smiling person is more reliable than a surly person. In job interviews and social interactions, an attractive and especially smiling face plays an important role. Studies have shown that better-looking individuals are perceived as more intelligent and qualified in job applications. ${ }^{4-6}$ All of these perceptions can be counted as factors that shape a patient's

\footnotetext{
1,2Department of Prosthetics, Faculty of Dentistry, Baskent University, Ankara, Turkey
}

Corresponding Author: Sadık H Uluçam, Department of Prosthetics, Faculty of Dentistry, Baskent University, Ankara, Turkey, Phone: +90 533 8648468, e-mail: drulucam@gmail.com

How to cite this article: Uluçam SH, Acar Ö. Esthetic Analyses in Dentistry. Int J Prosthodont Restor Dent 2019;9(3):88-92.

Source of support: Nil

Conflict of interest: None

expectations. This suggests that dentists should better understand some esthetic concepts that will enhance the smile in a better way.

In another saying, laughter is a person's ability to express her/his various emotions through the tooth, lip structure, and movement. Studies have shown that individuals with poor dental esthetics are less attractive in society. ${ }^{6-8}$ Various designs, proportions, and objective standards have been set in order to improve the smile. These analyses and standards are among the components that should be integrated into comprehensive treatment planning in cases with esthetic concerns.

\section{Esthetic Analyses}

Esthetic analyses used in dentistry can be examined under four main subjects: ${ }^{9}$

- Facial analyses

- Dentolabial analyses

- Dental analyses

- Phonetic analyses

\section{Facial Analyses}

A proportional face can be divided into three equal parts using horizontal lines as reference. The upper $1 / 3$ of the face is located between the scalp line and the line passing through the eyebrows. The middle $1 / 3$ is between the line passing through the nose wings and the brow line. The lower $1 / 3$ extends from the nose wings to the tip of the chin. ${ }^{2,9}$

Due to the presence of teeth and lips, the lower $1 / 3$ of the face is the most remarkable area. The upper $1 / 3$ of this area is formed by the upper lip and the lower $2 / 3$ by the lower lip and chin. ${ }^{9}$ 
The interpupillary line is the straight line passing through the pupils of the eyes and is the most appropriate reference for an accurate facial analysis if it is parallel to the horizontal plane. Ophriac line, commissural line, and interalar line are as a rule parallel to the interpupillary line. These lines, which are referenced in frontal view, are used to determine the contour of the cutter plane, the occlusal plane, and the gingiva. ${ }^{2,3,9}$

The facial midline is positioned perpendicular to the interpupillary line in the center of the face. It is also defined vertically as nasion, subnasal point, interincisal point, and an imaginary line passing over the pogonion. Dental midline and skeletal midline coincide with each other. In clinical practice, the upper jaw dental and skeletal midline overlap in $70 \%$ of the population. ${ }^{10}$

The midline of the face is the critical starting point of dental esthetics. Most patients show facial asymmetries. All deviations of the maxillary dental midline relative to the facial midline have the potential to have a negative impact on the smile. Therefore, the line between the facial midline and the maxillary central incisors should overlap as much as possible. ${ }^{9}$

Studies have shown that the acceptable average threshold value of midline deviation is $1.5-2.2 \mathrm{~mm} .{ }^{10,11}$ If the incisal midline and the facial midline do not overlap, the midlines should be parallel to each other. Studies have shown that midline shifts of up to $4 \mathrm{~mm}$ are not noticed by dentists and non-occupational individuals as long as the face midline and dental midline parallelism is maintained. If the midlines are not parallel, it may create a non-esthetic appearance and should be avoided. The data obtained in this regard show that dentists can detect dental angulation of more than 6 degrees and non-professional individuals can recognize the angulations more than 10 degrees. ${ }^{12}$ If the difference between the facial midline and the teeth is small, and if the patient does not have a special desire; then there is no need to do any special treatment.

The profile is determined by the angle formed when the three reference points on the face come together; these are glabella, nasal point, and chin tip. The angle between these three points generally is about 170 degrees and forms a normal profile. This angle decreases on the faces with convex profile. Convexity depends on the chin tip being at a more posterior than the normal profile. In the concave profile, the angle joining the three points is greater than 180 degrees. Extreme convexity or concavity refers to skeletal class II or III, respectively. However, convexity or concavity may not indicate whether the maxilla or mandible is in protrusion or retrusion. Ricketts' E-line is the line that connects the tip of the nose with the tip of the chin, which is used to determine the position of the lips. In an ideal profile, the upper lip is $4 \mathrm{~mm}$ behind the $E$ line while the lower lip is $2 \mathrm{~mm}$ behind. ${ }^{13}$ The nasolabial angle consists of a combination of two lines in the subnasal region. One is the line that tangents to the tip of the nose, and the other one is the line that tangents to the outer end of the upper lip. In individuals with a normal profile, the nasolabial angle ranges from 90 degrees to 95 degrees for men and from 100 degrees to 105 degrees for women. The labial filtrum is $2-3 \mathrm{~mm}$ shorter than the distance of the labial commissura to the base of the nose. In young individuals, shorter measurements of labial filtrum values are observed and this makes upper central teeth more visible. This analysis may be useful in determining the axial inclinations of the anterior teeth and lip support in prosthetic restorations. . $^{3,9,13-16}$

\section{Dentolabial Analyses}

In dentolabial analyses, lip movements, the number of teeth visible in resting position, the inclination of the incisors and the relation with the lower lip, the smile line, and the width of the smile are evaluated.

Observation of lip movements allows the determination of the number of teeth that becomes visible during smile and speech. When the teeth are at the maximum intercuspal position, the lips are in slight contact with each other and the incisal 1/3 of the upper incisors slightly touches the wet portion of the lower lip. When the mandible is in resting position, the teeth do not contact with each other, the lips are slightly open; and the incisal $1 / 3$ of the upper incisors are visible. This amount varies between $1 \mathrm{~mm}$ and $5 \mathrm{~mm}$ that depends on the patient's age, sex, and lip height. The mean incisal appearance is $1.91 \mathrm{~mm}$ in men and $3.4 \mathrm{~mm}$ in women. As the age progresses, the upper teeth visibility decreases; and the lower teeth visibility increases. ${ }^{9,17,18}$

The gradient of the incisal edge consists of the incisal edges of the maxillary anterior teeth, which is parallel to the inner slope of the lower lip and is also called as the smile curve. The gradient of the occlusal plane varies as more or less prominent. When evaluating the relationship between the gradient of the incisal plane and the lower lip in the population, a parallel-concave relationship is observed with incisors of the maxillary anterior teeth at a rate of $60 \%$, while a straight-to-convex relationship is observed with a rate of $34 \%$. Parallel-convex and flat smile curve is considered more esthetic than a reverse-concave smile curve. Ideal incisal plane slope, length, and angulation of the maxillary incisors are affected by factors, such as maxillary arch width, the lower lip curvature, and occlusal plane. Convexity of the incisal plane and anterior teeth with ideal ratios forms a central symmetry.

If a smile is to be defined as ideal, the upper lateral incisors should be 0.5-1.5 mm away from the lower lip and the upper central teeth and canines should be very close to the lower lip line. ${ }^{10}$ This can be achieved by making central teeth more prominent than lateral teeth. The inclinations drawn by the incisal edge and the lower lip vary among patients. In many cases, there is a significant gap between the incisal edge and the lower lip. In order to create a harmonious esthetic structure, the lower lip and incisal plane must form a parallel slope in each case. ${ }^{10}$ The physician should decide whether the inclination should be made parallel to the abnormal lip slope or to the horizontal reference plane when planning the treatment.

When analyzing the smile line, the first step is to determine how much anterior teeth appear while smiling. With a low smile line, upper lip movements can cause the appearance of anterior teeth to be $75 \%$ or less. With the middle smile line, lip movements can make the anterior teeth appear to be between $75 \%$ and $100 \%$, and also interproximal papillae can be seen. With a high smile line, all of the anterior teeth can be seen during smiling and also a small amount of gingiva can be seen. A beautiful smile can be defined as the appearance of approximately $1 \mathrm{~mm}$ of gingival tissue with the appearance of the entire upper teeth. ${ }^{20-22}$

Gummy smile (appearance of gingiva more than 3-4 mm) is considered an esthetically poor by patients. For gummy smile patients, orthognathic and orthodontic treatments are the most suitable options, especially in the presence of healthy teeth. In these cases, periodontal surgical procedures are also used when planning esthetic prosthetics. Gingival margin levels can also be rearranged by crown lengthening. One of the current popular 
gummy smile treatment options is an injection of botulinum toxin to minimize upper lip movements making the gingiva visible when smiling. ${ }^{21,23-25}$

The number of teeth that become visible when smiling varies between people. In the majority of society, 10 maxillary teeth become visible while smiling. The type of preparation on the buccal side of teeth and the choice of restorative material to be used plays a decisive role while analyzing the width of the smile. The region which is defined as a buccal corridor will contribute to the esthetics by adding distance and depth illusion to the restorations if it is ideal in frontal appearance. If the restorations are made regardless of the buccal corridor and the area is filled with restorations, an artificial image in the form of a white block will be obtained. If this area is insufficient during prosthetic treatment, the clinician should make more preparation on the axial walls of teeth and achieve the required space for restoration and the buccal corridor. ${ }^{17,26-28}$

\section{Dental Analyses}

Dental analyses can be examined under three main subjects; interincisal line, tooth shape, and tooth color.

Vertical lines between upper and lower incisors are defined as interincisal line. The slight discordance of the lines between the upper and lower incisors is rarely recognized by patients and does not create a significant issue while forming an ideal esthetic. It will add a natural look to the smile. This can be achieved by making modifications to the teeth axles. However, the deviations in the tooth axles are very easy to notice. Therefore, it is important to maintain the axial slope and not to make radical changes. ${ }^{12,29-32}$

The tooth shape is genetically determined and varies between people. ${ }^{10}$ The esthetic aim of the prosthesis is to make the teeth look natural. This can be achieved by combining the patient's personality, age, and sex together in harmony. The anatomical features of young teeth are more evident, lighter in color, and have lower chroma. In addition, gingival margins of young teeth are approximately at the cementoenamel junction. They also have characteristic incisal edges, prominent incisal edges, small gingival embrasures, and white hypoplastic lines and dots that make lateral incisors appear shorter than central incisors and canines. In older patients, teeth color darkens, chroma increases, and the incisal edges become shorter. For these reasons, fewer teeth appearance, smaller incisal embrasures, wider and open gingival embrasures can be observed. ${ }^{18}$ The mesial or distal angulation of the maxillary incisors can have dramatic effects on esthetics. While mild mesial angulation is generally acceptable, distal angulation should be avoided. ${ }^{9,30}$

The most common classification of form is square, triangular, and oval. Teeth with regular shapes, which are generally compatible with lip contour, close to the square or oval form, are preferred by patients, while triangular tooth forms are less preferred. The idea of female and male tooth form divided by sex is controversial. ${ }^{30}$ In order to facilitate teeth shape selection, Lombardi, Frush, and Fisher created a schema by age, sex, and character; but this schema was not found to be very useful in practice. ${ }^{33,34}$ The photographs or models of the patient's old teeth are very useful while deciding the teeth form of the prosthesis to be made. ${ }^{9}$

\section{Golden Ratio}

The relative proportions of the six maxillary anterior teeth with each other is another analytical situation related to the tooth shape. Many clinicians accept and apply the golden ratio principles in dentistry. ${ }^{9}$ The golden ratio is based on formulas defined by ancient Greek mathematicians. This ratio was widely used in the architecture of the Parthenon temple. This concept was first mentioned by Lombardi and later developed by Levin. ${ }^{33,35}$ The golden ratio suggests that the ideal mathematical ratio is 1,618. However, the stiffness of the mathematical formula and the variety between the patients have led a controversy over the reliability of this principle. Forster et al. have reported the average width between teeth. ${ }^{36} \mathrm{~A}$ dental faculty in Hungary have found a ratio of 1.6/1/0.85 in their research group. Hasanreisoglu et al. reported that the central incisors were narrower and the canines were wider than the gold ratio of $1.6 / 1 / 0.60 .{ }^{37}$ Orozco-Varo et al. have studied a biometric analysis of clinical crown width/length ratios in the maxillary anterior region. Their study group was European people and the ratio they have found of comparing the maxillary central incisor width to the lateral incisor width was $1.27 / 1 .^{38}$ They stated that this ratio does not correspond to the golden ratio. ${ }^{38}$ Preston conducted studies related to the golden ratio and found that only the ratios between the central incisors and the lateral incisors have corresponded to the golden ratio. Preston also stated that there is no correlation between all the other ratios in the mouth with the golden ratio. He has suggested the use of the Preston ratio, stating that the maxillary lateral incisor width at the frontal view should be $66 \%$ of the central incisor width and $84 \%$ of the lateral incisor width at the frontal view instead of the golden ratio. ${ }^{34}$ When we compile different studies from all around the world, it was revealed that ethnic and regional characteristics should be considered in restorations instead of golden ratio. ${ }^{9,30,35-37,39-41}$

\section{Recurring Esthetic Dental Proportion}

It is presented as a model in smile design. This dimension states that, from the frontal view, there is a constant ratio between the widths of successive teeth towards the distal. Towards the posterior, the width of each maxillary tooth decreases by a certain percentage. This is a two-dimensional evaluation of three-dimensional smile. Thus, the buccopalatal position of the teeth affects their width appearance. The recommended recurring esthetic dental (RED) proportion range is $62-80 \%$. In a survey conducted among dentists regarding the RED proportion; the ratio of $80 \%$ for very short teeth, $70 \%$ ratio for normal length teeth, and $62 \%$ ratio for long teeth was found esthetic by the majority. ${ }^{42}$ First, the ideal size of the central incisor is calculated, then it is multiplied by the desired RED proportion to determine the width of the lateral incisor from the frontal. While the natural width/length ratio of the central incisors is $85-86 \%$, in most of the studies clinicians preferred $75-78 \%$ width/ length ratio. $30,40,42,43$

\section{Anterior Interproximal Contact Area}

The interproximal contact area is the area between the gingival and incisal embrasures of two adjacent tooth. This area is sometimes referred to as connector space. In contrast, the connector space defines the visible contact of two adjacent tooth, i.e., a larger area. However, the point of contact actually refers to the area in which the tooth come into contact. The ideal esthetic results are obtained if the area of connector space is; $50 \%$ between the central incisors, $50 \%$ to $40 \%$ between the central and lateral incisors and $40 \%$ to $30 \%$ between the lateral incisors and canine teeth. The contact points relocate towards the apical from the central incisor to the canine, and the interincisal angles enlarge from mesial to distal. The lines merging from the interdental contact points and the parallelism of the maxillary incisal arch and lower lip arch provide more esthetic results. ${ }^{9,18,30}$ 


\section{Gingival Zenith}

Gingival zenith is the most apical area of the clinical crown. Its shape and location are determined by the gingival structure and dental anatomy. It is typically located in the middle and distal triple junction in the facial appearance of the tooth. In contrast, lateral incisors are more varied and can be observed to overlap the exact midpoint of the gingival zenith. To ensure optimal esthetic appearance, it should be assessed whether gingival zenith has sufficient contour. The positions of the zenith points are important in closing the diastemas or in correcting the distal or mesial tipping of the teeth. By periodontal surgery or using temporary restorations, new forms of the gingival zenith areas can be achieved. To establish ideal gingival zeniths, the first option is gingivectomy, which is to remove the gingiva in the desired form by minor surgery. $9,18,30,44,45$

\section{Tooth Color}

The appearance and color of the teeth is a complex phenomenon that includes factors, such as lighting conditions (light source, time factor in daylight), translucency, opacity, reflecting light, brightness, environmental conditions, and perception of the human eye and brain. ${ }^{30}$ Light consists of different wavelengths and one tooth can be seen in different colors under different light conditions. This phenomenon is called "metamerism." The system defining the tooth color developed by Albert Henry Munsell in 1915 is still a standard today. This system divides color into three parameters: hue, chroma, and value. In addition to Munsell's color system, International Commision on Illumination (CIE-Lab), and red, green, blue (RGB) color systems are among the most commonly used color systems. In decision of tooth color, scales, spectrophotometric measurements, and computerized measurements of digital images can be helpful. ${ }^{16}$

When natural teeth examined, a significant difference in color can be found between two arcs. It is frequently observed that the upper incisors are the lightest colored teeth in the mouth, and therefore not only because of their size but also because of their brightness, the most dominant teeth of the mouth are the upper central incisors. There is a transition in the colors and shades of the maxillary teeth starting from the midline. Although lateral incisors and central incisors have a similar tone, lateral incisors have less brightness. Of all anterior teeth, canine teeth have the highest saturation and lowest brightness. Although they are lighter and brighter than canine teeth, first and second premolar are similar to lateral incisors in terms of brightness. Considering these information, when creating a natural look in any anterior restoration, it is important to use different shades even if the patient requests the lightest shades. ${ }^{2,9}$

\section{Phonetic Analyses}

Phonetic analyses are used to determine the placement of the teeth, appropriate anterior teeth position, and anterior teeth length. In 1950s, clinicians addressed the importance of phonetics in determining appropriate anterior tooth position and length according to the occlusion vertical dimension. ${ }^{46}$

When the patient pronounces " $\mathrm{M}$ " letter, the teeth will be at the resting position. It can be used as a phonetic guide to obtain initial wax-up in well-planned cases. ${ }^{9}$

Pronunciation of letter " $E$ " for an extended while, is another important phonetic guide. This sound usually indicates the widest smile. When this sound is pronounced, the space between the lower and upper lips should be filled almost completely by the maxillary incisors. ${ }^{9}$
Since they have an important role in both anterior guidance and phonetics, the length of the maxillary incisors should not be evaluated solely from the esthetic aspect. If the length is correct, the maxillary incisal edges should be placed on the inner side of the vermillion line of the lower lip when the patient makes the " $\mathrm{F}$ " sound. The correct pronunciation of the " $\mathrm{F}$ " and " $\mathrm{V}$ " letters is achieved by the slight contact of the maxillary anterior teeth with the lower lip. The incisal edges should be positioned on the line forming the wet-dry border of the lower lip. This light contact provides sufficient pressure for correct pronunciation. ${ }^{9,47}$

The " $\mathrm{S}$ " sound is generated by the air passing between the soft surface of the tongue and the palatal surface of the maxillary anterior teeth. While determining the positions of incisal edges of mandibular incisors, both the occlusion with the maxillary incisors and the positions of the mandibular incisal edges which is $1 \mathrm{~mm}$ posterior and $1 \mathrm{~mm}$ inferior while pronouncing " $\mathrm{S}$ " sound should be considered. ${ }^{48}$

Phonetic analyses are safe guidelines for proper esthetic evaluation and for a functional diagnosis. Therefore, one of the purposes of a correct restoration is to provide a good phonation. In cases where phonation and dentofacial analyses conflict, choices should be made according to the case by the experience of the clinician. ${ }^{9,18,49}$

\section{Conclusion}

In the light of this information, esthetic and cosmetic treatments to be performed considering esthetic analyses will provide the clinician an artistic perspective in accordance with professional ethics. At the same time, this can increase patient satisfaction by meeting the subjective esthetic expectation of the patient with objective data and criteria.

\section{References}

1. Nash DA. Professional ethics and esthetic dentistry. J Am Dent Assoc 1988;117(4):7E-9E.

2. Romano R. The Art of the Smile. Integrating Prosthodontics, Orthodontics, Periodontics, Dental Technology, and Plastic Surgery in Esthetic Dental Treatment. Germany: Quintessence Publishing; 2005.

3. Gurel G. Porselen laminat venerler. Blilim ve sanatı. İstanbul: Quintessence Yayıncılık; 2004.

4. Langlois JH, Kalakanis L, Rubenstein AJ, et al. Maxims or myths of beauty? A meta-analytic and theoretical review. Psychol Bull 2000;126(3):390-423. DOI: 10.1037/0033-2909.126.3.390.

5. Nordholm LA. Beautiful patients are good patients: evidence for the physical attractiveness stereotype in first impressions of patients. Soc Sci Med 1980;14A(1):81-83.

6. Henson ST, Lindauer S, Gardner W, et al. Influence of dental esthetics on social perceptions of adolescents judged by peers. Am J Orthod Dentofacial Orthop 2011;140(3):389-395. DOI: 10.1016/ j.ajodo.2010.07.026.

7. Dion K, Berscheid E, Walster E. What is beautiful is good. J Pers Soc Psychol 1972;24(3):285-290. DOI: 10.1037/h0033731.

8. Newton JT, Prabhu N, Robinson PG. The impact of dental appearance on the appraisal of personal characteristics. Int J Prosthodont 2003;16(4):429-434.

9. Fradeani M. Esthetic analysis: a systematic approach to prosthetic treatment. Esthetic rehabilitation in fixed prosthodontics; 2004. pp. 137-153.

10. Sharma PK, Sharma P. Dental smile esthetics: the assessment and creation of the ideal smile. Semin Orthod 2012;18(3):193-201. DOI: 10.1053/j.sodo.2012.04.004. 
11. Johnston CD, Burden DJ, Stevenson MR. The influence of dental to facial midline discrepancies on dental attractiveness ratings. Eur J Orthod 1999;21(5):517-522. DOI: 10.1093/ejo/21.5.517.

12. Thomas JL, Hayes $\mathrm{CL}$, Zawaideh $\mathrm{S}$. The effect of axial midline angulation on dental esthetics. Angle Orthod 2003;73(4):359-364. DOI: 10.1043/0003-3219(2003)073<0359:TEOAMA>2.0.CO;2.

13. Ricketts RM. The biologic significance of the divine proportion and Fibonacci series. Am J Orthod 1982;81(5):351-370. DOI: 10.1016/00029416(82)90073-2.

14. Davis NC. Smile design. Dent Clin North Am 2007;51(2):299-318. DOI: 10.1016/j.cden.2006.12.006.

15. Calamia JR, Levine JB, Lipp $M$, et al. Smile design and treatment planning with the help of a comprehensive esthetic evaluation form. Dent Clin North Am 2011;55(2):187-209. DOI: 10.1016/ j.cden.2011.01.012.

16. Rosenstiel SF, Land MF. Principles of Tooth Preparation. Contemporary Fixed Prosthodontics. E.H. Sciences; 1997.

17. Shillingburg HT, Hobo $S$, Whitsett $L$, et al. Fundamentals of Fixed Prosthodontics, 3rd ed., Quintessence Publishing; 1997.

18. Bhuvaneswaran M. Principles of smile design. J Conserv Dent 2010;13(4):225-232. DOI: 10.4103/0972-0707.73387.

19. Frese $C$, Staehle HJ, Wolff D. The assessment of dentofacial esthetics in restorative dentistry: a review of the literature. J Am Dent Assoc 2012;143(5):461-466. DOI: 10.14219/jada.archive.2012.0205.

20. Arias DM, Trushkowsky RD, Brea LM, et al. Treatment of the patient with gummy smile in conjunction with digital smile approach. Dent Clin North Am 2015;59(3):703-716. DOI: 10.1016/j.cden.2015. 03.007.

21. Levine RA, McGuire M. The diagnosis and treatment of the gummy smile. Compend Contin Educ Dent 1997;18(8):757-762, 764; quiz 766.

22. Geron S, Atalia W. Influence of sex on the perception of oral and smile esthetics with different gingival display and incisal plane inclination. Angle Orthod 2005;75(5):778-784. DOI: 10.1043/0003-3219(2005)75[778:IOSOTP]2.0.CO;2.

23. Sarver DM. Principles of cosmetic dentistry in orthodontics: Part 1. Shape and proportionality of anterior teeth. Am J Orthod Dentofacial Orthop 2004;126(6):749-753. DOI: 10.1016/j.ajodo.2004.07.034.

24. Espana P, Tarazona B, Paredes V. Smile esthetics from odontology students' perspectives. Angle Orthod 2014;84(2):214-224. DOI: 10.2319/032013-226.1.

25. Polo M. Botulinum toxin type A (Botox) for the neuromuscular correction of excessive gingival display on smiling (gummy smile). Am J Orthod Dentofacial Orthop 2008;133(2):195-203. DOI: 10.1016/ j.ajodo.2007.04.033.

26. Maulik C, Nanda R. Dynamic smile analysis in young adults. Am J Orthod Dentofacial Orthop 2007;132(3):307-315. DOI: 10.1016/ j.ajodo.2005.11.037.

27. Zange $\mathrm{SE}$, Ramos AL, Cuoghi OA, et al. Perceptions of laypersons and orthodontists regarding the buccal corridor in long- and short-face individuals. Angle Orthod 2011;81(1):86-90. DOI: 10.2319/031210145.1.

28. Parrini S, Rossini G, Castroflorio T, et al. Laypeople's perceptions of frontal smile esthetics: a systematic review. Am J Orthod Dentofacial Orthop 2016;150(5):740-750. DOI: 10.1016/j.ajodo.2016.06.022.

29. Silva BP, Jiménez-Castellanos E, Stanley K, et al. Layperson's perception of axial midline angulation in asymmetric faces. J Esthet Restor Dent 2018;30(2):119-125. DOI: 10.1111/jerd.12347.
30. LeSage BP, Dalloca L. Approaches to smile design: mathematical to artistic Interpretation. J Cosmetic Dental 2012;28(1):126-149.

31. Fernandes $L$, Pinho $T$. Esthetic evaluation of dental and gingival asymmetries. Int Orthod 2015;13(2):221-231. DOI: 10.1016/ j.ortho.2015.03.005.

32. Silva $B P$, Jiménez-Castellanos $E$, Martinez-de-Fuentes $R$, et al. Perception of maxillary dental midline shift in asymmetric faces. Int J Esthet Dent 2015;10(4):588-596.

33. Lombardi RE. The principles of visual perception and their clinical application to denture esthetics. J Prosthet Dent 1973;29(4):358-382. DOI: 10.1016/s0022-3913(73)80013-7.

34. Frush JP, Fisher RD. The dynesthetic interpretation of the dentogenic concept. J Prosthet Dent 1958;8(4):558-581.

35. Levin E. Dental esthetics and the golden proportion. J Prosthet Dent 1978;40(3):244-252. DOI: 10.1016/0022-3913(78)90028-8.

36. Forster A, Velez R, Antal M, et al. Width ratios in the anterior maxillary region in a Hungarian population: addition to the golden proportion debate. J Prosthet Dent 2013;110(3):211-215. DOI: 10.1016/S00223913(13)60359-5.

37. Hasanreisoglu U, Berksun S, Aras K, et al. An analysis of maxillary anterior teeth: facial and dental proportions. J Prosthet Dent 2005;94(6):530-538. DOI: 10.1016/j.prosdent.2005.10.007.

38. Orozco-Varo A, Arroyo-Cruz G, Martínez-De-Fuentes R, et al. Biometric analysis of the clinical crown and the width/length ratio in the maxillary anterior region. J Prosthet Dent 2015;113(6):565-570. DOI: 10.1016/j.prosdent.2014.11.006.

39. Ward DH. A study of dentists' preferred maxillary anterior tooth width proportions: comparing the recurring esthetic dental proportion to other mathematical and naturally occurring proportions. J Esthet Restor Dent 2007;19(6):324-339. DOI: 10.1111/j.17088240.2007.00114.x

40. Preston JD. The golden proportion revisited. J Esthet Dent 1993;5(6):247-251. DOI: 10.1111/j.1708-8240.1993.tb00788.x.

41. Mack MR. Vertical dimension: a dynamic concept based on facial form and oropharyngeal function. J Prosthet Dent 1991;66(4):478-485. DOI: 10.1016/0022-3913(91)90508-t.

42. Rosenstiel SF, Ward DH, Rashid RG. Dentists' preferences of anterior tooth proportion--a web-based study. J Prosthodont 2000;9(3): 123-136.

43. Ward DH. Proportional smile design: using the recurring esthetic dental proportion to correlate the widths and lengths of the maxillary anterior teeth with the size of the face. Dent Clin North Am 2015;59(3):623-638. DOI: 10.1016/j.cden.2015.03.006.

44. Miranda ME, Olivieri KA, Rigolin FJF, et al. Esthetic challenges in rehabilitating the anterior maxilla: a case report. Oper Dent 2016;41(1):2-7. DOI: 10.2341/14-269-S.

45. Pinho S, Ciriaco C, Faber J, et al. Impact of dental asymmetries on the perception of smile esthetics. Am J Orthod Dentofacial Orthop 2007;132(6):748-753. DOI: 10.1016/j.ajodo.2006.01.039.

46. Bloom DR, Padayachy JN. Increasing occlusal vertical dimensionwhy, when and how. Br Dent J 2006;200(5):251-256. DOI: 10.1038/ sj.bdj.4813305.

47. Morris JB. Functional occlusion: from TMJ to smile design. J Prosthodont 2008;17(3):251.

48. Pound E. Let/S/be your guide. J Prosthet Dent 1977;38(5):482-489. DOI: 10.1016/0022-3913(77)90022-1.

49. Çalıkkocaoğlu S. Dişsiz Hastaların Protetik Tedavisi Klasik Tam Protezler. İstanbul: Quintessence Yayıncllık; 2010. 